\title{
TAUROMAQUIA E IDENTIDAD MORAL DE CATALUÑA
}

En todas las sociedades hay pueblos con un mayor nivel de progreso ético y otros que lo tienen en menor grado.

A partir de la década de los 90 del pasado siglo, al único índice utilizado hasta entonces -el nivel de ingreso o de producción "per cápita"- se une el de Desarrollo Humano del PNUD (Programa de las Naciones Unidas para el desarrollo), y poco a poco se agregaron otros como el de transparencia o la Huella Ecológica ${ }^{1}$.

Igualmente, el tipo de capital del que una sociedad dispone se mide por el capital físico, el humano (recursos humanos) y el social, siendo este último uno de los puntales de la identidad moral catalana. Y dentro de él, el CAPITAL ÉTICO es parte fundamental en la construcción de la identidad.

Siguiendo a la filósofa Adela Cortina, diremos que "el capital ético existente en una sociedad, constituido por los valores morales que un pueblo comparte" es lo que CONFORMA LA IDENTIDAD MORAL ÉTICA DE UN PUEBLO, lo que hace que en toda sociedad existan valores éticos que actúan como referente para juzgar las actuaciones de los miembros de dicha sociedad ${ }^{2}$.

Lo que pretendo demostrar es que uno de los valores que conforman la IDENTIDAD MORAL Y ÉTICA DEL PUEBLO CATALÁN es una alta sensibilidad hacia el bienestar de los animales y un rechazo al maltrato, sin opciones a exclusión por estética, tradición o difusión desde otras culturas.

Otro punto, no menos importante, incluido por el Banco Mundial dentro del capital social, es LA CONFIANZA EN LA PALABRA DADA POR SUS AUTORIDADES,

\footnotetext{
${ }^{1}$ Informe Final Mesa Programa Nacional de Voluntariado. Elementos para una política pública de fomento del voluntariado en Chile. Santiago, Diciembre de 2007. Pag. 19

${ }^{2}$ A.CORTINA, conferencia en el Forum de Barcelona el 25/07/2004, en la sesión sobre el capital ético y el desarrollo en el marco del Diálogo "La riqueza ética de las naciones. Valores y desarrollo social"
} 
EN EL COMPROMISO POR ELLAS ADQUIRIDO, lo que implica no solo respetar los acuerdos de los municipios catalanes que se han declarado contrarios a las prácticas de las corridas de toros -como el alcanzado en sesión plenaria del Consejo Municipal de Barcelona de 6 de Abril de 2004 - y valorar con criterios que forman parte de la Identidad Moral catalana las comparecencias que están teniendo lugar ante el Parlament de Catalunya, sino también respetar las declaraciones de principios con las que se han presentado ante los electores.

En este sentido, no se pueden entender noticias como la aparecida en los medios informativos de Castilla y León ${ }^{3}$ en la que, literalmente, se dice: "los socialistas catalanes votarán en bloque si a que se sigan celebrando corridas de toros en Cataluña. Los socialistas de Castilla y León les han explicado la importancia económica que tiene para la Comunidad la cría del toro bravo". Parece que la reunión con los socialistas castellano-leoneses, con ganaderos "llegados de varios puntos de España y matadores de toros..." tiene más peso específico que los informes técnicos de expertos que se desarrollan en el Parlament, habiendo decidido ya el voto antes de escuchar las alegaciones que aquí están teniendo lugar. Tampoco esto encaja ni con la identidad catalana ni, si me lo permiten, con los valores proclamados por el socialismo ${ }^{4}$

Es curiosa, por otro lado, la noticia recogida en la edición de "Crónica catalana" del 2 de marzo sobre los galardones otorgados a algunos diputados que van a defender la tauromaquia, unos acogiéndose a la libertad de voto y otros porque su partido no la otorga $^{5}$.

Encontré el extracto de un discurso pronunciado por Artur $\operatorname{Mas}^{6}$ que enlaza perfectamente con esta idea. En la página 14, dice: Deixeu-m'ho resumir en una sola frase: el catalanisme s'ha d'ocupar de l'ànima de la nació. En el món catalanista hi ha molts debats oberts; però gairebé cap sobre l'ànima de la nació, que és allò que la fa gran, pròspera, sentida i estimada.

\footnotetext{
${ }^{3}$ rtvcyl.es, 28/02/2010

${ }^{4}$ http://www.socialistes.cat/psc esl/El-Partido/Presentacion/Valores.

${ }^{5}$ crònica.cat 02/03/2010. Guardonen diputats de CIU, PSC, PP i C's per estar a favor de les curses de braus

${ }^{6}$ ARTUR MAS, El catalanisme, energia i esperança per a un país millor, en Revista Catalana de Pensamiento social "La Factoría”,no 34, 2007, (http://www.revistalafactoria.eu/articulo.php?id=8 )
} 
Para G.H. Mead ${ }^{7}$, es evidente la relación entre identidad y acción colectiva, ya que la conducta social solo puede entenderse en función del grupo social del que se forma parte, pues los actos individuales abarcan a otros miembros del grupo. La conciencia debe de entenderse como un proceso social.

Por su parte T. Parsons ${ }^{8}$ nos dice que la socialización se forma por interiorización de valores, normas y códigos culturales muy generalizados y compartidos, siempre mediados por el sistema social.

Todo esto, finalmente, formará parte del trabajo del "Grupo de Investigación Cultura e Identidad Moral" dirigido por el Dr. A. Verbrugge, de la Universidad de Ámsterdam, que investiga la relación entre los marcos culturales morales, la justicia de la sociedad y la identidad moral ${ }^{9}$.

Para este grupo de investigadores, la identidad moral de un pueblo, el marco moral común, es fundamental para el buen desarrollo para alcanzar la madurez moral. En ese marco moral es donde el "alma" de un pueblo está íntimamente relacionada con la forma en la que las personas experimentan su propia vida y en como ven la forma en la que lo hacen los demás.

Enlaza aquí con el estudio sobre "Estadios evolutivos del razonamiento moral", llevado a cabo por Kohlberg ${ }^{10}$, que al hablar de los estadios correspondientes al nivel posconvencional nos dice en el $5^{\circ}$ "Derechos prioritarios y contrato social": ...se asume que las leyes legítimas son sólo aquéllas obtenidas por consenso o contrato social. Ahora bien, si una norma va contra la vida o la libertad, se impone la obligación moral de no aceptarla y de enfrentarse a ella.

En el 60, "Principios éticos universales": Se toma conciencia que hay principios éticos universales que se han de seguir y tienen prioridad sobre las obligaciones legales $e$

\footnotetext{
${ }^{7}$ G.H. MEAD, Espíritu, Personalidad y Sociedad, 1993

${ }^{8}$ T. PARSONS. El sistema social, 1988

${ }^{9}$ Programa del grupo de Investigación Culture and moral identity http://www.wijsbegeerte.vu.nl/nl/onderzoek/secties/praktische-filosofie/culture-and-moral-identity/index.asp

${ }^{10} \mathrm{http} / /$ www.xtec.cat/ lvallmaj/passeig/kohlberg.htm
} 
institucionales convencionales...En este estadio impera la regla de oro de la moralidad: "hacer al otro lo que quiero para mi". Y se tiene el coraje de enfrentarse a las leyes que atentan a los principios éticos universales...Es el estadio moral supremo, el de Gandhi, de Martin Luther King y el de todas las personas que viven profundamente la moralidad. Y, POR TANTO, LAS CORRIDAS DE TOROS NO PUEDEN ENCAJAR DENTRO DE ESTOS PRINCIPIOS ÉTICOS UNIVERSALES.

Susana Frisancho ${ }^{11}$ nos dice: La escuela es uno de los espacios fundamentales en los que ocurre el desarrollo humano. Si queremos que este desarrollo sea pleno, y que la escuela forme individuos con conciencia ética, capaces de reconocer y respetar los derechos humanos fundamentales, ésta tiene que hacerse cargo de la construcción de las identidades morales de los estudiantes... La escuela entonces debe apuntar a la construcción de identidades morales, y trabajar, en la medida de lo posible, para que estas identidades tengan compromisos éticos auténticos.

Cuando se quiere crear una identidad diferente a la que se tiene, es necesario un doble ejercicio: de memoria histórica y de olvido selectivo ${ }^{12}$ No se puede creer en la posibilidad de que las corridas de toros encajen en la ética del marco identitario del pueblo catalán sin antes intentar borrar la memoria de su larga tradición en la defensa de los animales y su horror a las fiestas con derramamiento de sangre

Si hablamos de tradición, NO SOLO LAS FIESTAS TAURINAS TIENEN UNA LARGA TRADICIÓN, aunque las tradiciones han de cambiar para adaptarse a los nuevos tiempos y a la ética que los acompaña. A lo largo de la Historia han sido numerosas las manifestaciones de la falta de ética de las corridas de toros. Algunas de ellas de distinto signo: religioso y político, ninguna de ellas venida desde culturas extrañas a nuestra herencia cultural mediterránea:

- Herencia occidental cristiana: San Pío V: Bula "DE SALUTIS GREGIS DOMINICI" (1576), aún vigente al estar blindada por el pontífice: ...Nos... prohibimos terminantemente por esta nuestra Constitución, que estará

\footnotetext{
${ }^{11}$ S. FRISANCHO. La identidad moral: elemento fundamental para una cultura de los Derechos Humanos, 2006

${ }^{12}$ M.DELGADO, Diversitat i integració. Lògica i dinàmic de les identitats a Catalunya 1.998:
} 
vigente perpetuamente, bajo pena de excomunión y de anatema en que se incurrirá por el hecho mismo, que todos y cada uno de los príncipes cristianos, cualquiera que sea la dignidad de que estén revestidos, sea eclesiástica o civil, incluso imperial o real o de cualquier otra clase, cualquiera que sea el nombre con el que se los designe o cualquiera que sea su comunidad o estado, permitan la celebración de esos espectáculos en que se corren toros y otras fieras es sus provincias, ciudades, territorios, plazas fuertes, y lugares donde se lleven a cabo. Prohibimos, asimismo, que los soldados y cualesquiera otras personas osen enfrentarse con toros u otras fieras en los citados espectáculos, sea a pie o a caballo. $Y$ si alguno de ellos muriere allí, no se le dé sepultura eclesiástica.

- Legislación en los regímenes ilustrados y liberales. Solo los absolutistas (Fernando VII) o las dictaduras (Primo de Rivera...) han apoyado la celebración de espectáculos taurinos.

○ 1785:"Pragmática sanción", de Carlos III, que prohíbe el espectáculo taurino.

○ 1796: "Memoria para el arreglo de la policía de los espectáculos y las diversiones públicas, y sobre su origen en España”, de Jovellanos, ministro de Carlos IV. Tiene frases como las siguientes:

- el clamor de sus censores, lejos de templar, irritó la afición de sus apasionados, y parecía empeñarlos más y más en sostenerle, cuando el celo ilustrado del piadoso Carlos III lo proscribió generalmente, con tanto consuelo de los buenos espíritus como sentimiento de los que juzgan las cosas por meras apariencias

- La lucha de toros no ha sido jamás una diversión, ni cotidiana, ni muy frecuentada, ni de todos los pueblos de España, ni generalmente buscada y aplaudida... ¿Cómo, pues, se ha pretendido darle el título de diversión nacional?

- sostener que en la proscripción de estas fiestas, que por otra parte puede producir grandes bienes politicos, hay el riesgo de que la nación sufra alguna pérdida real, ni en el orden moral ni en el civil, es ciertamente una ilusión, un delirio de la preocupación. 
- Congreso de los Diputados: 1894. Contra las corridas de toros. Madrid 31, 11'25 noche. Se ha presentado hoy al Congreso una proposición de ley solicitando la abolición de las corridas de toros. Firman esta proposición los republicanos señores Avila, Pi y Margall, Salmerón, Pedregal y Azcárate, el carlista señor Barrio y Mier y el ministerial señor Soldevilla. La proposición se extiende á todos los espectáculos análogos á las corridas de toros que produzcan sangre, lesiones, mutilaciones ó muerte de personas ó animales. Abolidos estos espectáculos, el Gobierno atenderá en la parte que pueda los intereses que resulten lesionados. $-S$. Edición del viernes, 01 junio 1894, página 5 - Hemeroteca Lavanguardia.es

Una vez vistos algunos de los trabajos más relevantes sobre la construcción de la identidad moral de los pueblos, y tras ver que las corridas de toros no son éticamente aceptables, paso a indicar la razón por la que la identidad moral catalana no puede estar de acuerdo con la celebración de corridas de toros.

Basta con dar un breve vistazo a la prensa catalana para darnos cuenta de una constante del pueblo catalán a lo largo de su historia: la defensa de los animales.

1900: Reunión de la Sociedad Protectora de la fauna y la Flora para tratar el tema de la abolición de las corridas de toros y nombrar un delegado para que viaje a París para reunirse con otras sociedades del mismo signo. Edición del sábado, 13 octubre 1900, página 2 - Hemeroteca - Lavanguardia.es

1903: Nota de prensa: Acuerdos de la Comisión Abolicionista de las Corridas de Toros en 1903: "Visitar AI señor alcalde para solicitar el apoyo de ésta autoridad en pro de los Ideales de la Comisión. Dirigir una circular a todos los maestros de Cataluña, pidiéndoles que inculquen en los niños aversión al espectáculo taurino. Inaugurar veladas antitaurinas, consistentes en cortas y sencillas conferencias y lectura de trabajos impresos ó manuscritos en contra de las corridas de toros, nombrar delegados de la Comisión en las principales poblaciones de España". Edición del martes, 10 marzo 1903, página 2 - Hemeroteca - Lavanguardia.es 
1904: Con motivo de la visita del Rey no se programa ningún festejo taurino para evitar disturbios. "Es llegado e momento de felicitar a quien dictó el acuerdo, de felicitar a Barcelona, de felicitarnos, en fin, todos los que tenemos amor al progreso y a nuestro país” Edición del martes, 12 abril 1904, página 2 - Hemeroteca - Lavanguardia.es

1904: Conferencia antitaurina. "Hoy, á las cuatro de la tarde, en la sociedad «Juventud Recreo-Instructivo», Puertaferrisa, 16, principal, dará una conferencia el señor Albi Morera sobre el tema siguiente: «Abolición de las corridas de toros en Barcelona para el bien de España»". Edición del domingo, 27 marzo 1904, página 3 $\underline{\text { Hemeroteca - Lavanguardia.es }}$

1904: Una organización del profesorado de Barcelona se adhiere a la campaña por la prohibición de las corridas de toros en domingo, como paso previo a su total abolición. Edición del martes, 02 agosto 1904, página 3 - Hemeroteca - Lavanguardia.es

1904: Telegrama cursado por la asociacion abolicionista de los toros al consejo de ministros: Edición del domingo, 17 septiembre 1905, página 2 - Hemeroteca Lavanguardia.es

1904: Carta de la Comisión Abolicionista al presidente de México: Edición del sábado, 16 abril 1904, página 2 - Hemeroteca - Lavanguardia.es

1905: Carta al director de La Vanguardia con el título de "Antitaurismo". El autor afirma: "Ignoro si el vocablo que sirve de epígrafe a estas líneas se halla contenido en el diccionario de la Real Academia Española, que no tengo á la vista; en caso negativo hará bien la docta corporación en darle carta de naturaleza en nuestro idioma, porque realmente hoy día tiene verdadero significado y representa una aspiración bien definida y arraigada en una gran parte del pueblo español. Pese a los pujos taurómacos de algunos elementos de las clases elevada y media, la afición popular torera decae, por mucho que lo quieran disimular los que tienen interés en mantener el status quo taurino". Edición del martes, 17 enero 1905, página 8 Hemeroteca - Lavanguardia.es

1905: Mitin antitaurino en el teatro Tívoli. Edición del martes, 14 febrero 1905, página 4 - Hemeroteca - Lavanguardia.es // Crónica del mitin. Lleno absoluto en el teatro e intento de reventar el acto por parte de los taurinos. Relación de propuestas de la Comisión Abolicionista. Entre otras, una que se recoge en la actual ley catalana. "3.' Denegar toda autorización para construir nuevas plazas de toros.no permitir la 
reedificación y que las actuales reúnan las necesarias condiciones de seguridad". Edición del martes, 14 febrero 1905, página 3 - Hemeroteca Lavanguardia.es

1905: Acto antitaurino convocado por la Comisión Abolicionista en los locales de Fraternidad Republicana Graciense, situado en el popular barrio de Barcelona. Edición del sábado, 03 junio 1905, página 2 - Hemeroteca - Lavanguardia.es

1906: El articulista celebra la proliferación de organizaciones de defensa del "medio ambiente". "Teníamos ya la Sociedad Protectora de animales y plantas, la que gestiona la abolición de las corridas de toros, de las riñas de gallos, etc. Funcionaba ya la que hace celebrar cada año la «fiesta del árbol». No bastaban. En lo sucesivo tendremos más y mejor. No sólo se protege á los animales de tiro y recreo-á pesar de que los amigos de la caza y de la pesca persisten en su manía homicida-, sino que se ha pensado en proteger de un modo efectivo la vida de las plantas". Edición del martes, 03 julio 1906, $\begin{array}{llllll}\text { página } & 6 & - & \text { Hemeroteca } & - & \text { Lavanguardia.es }\end{array}$

1907: En España todavía estaban permitidos los duelos, en lances llamados de honor, mientras se continuaban construyendo nuevas plazas de toros.Edición del lunes, 04 febrero 1907, página 4 - Hemeroteca - $\quad$ Lavanguardia.es

1909: Noticia de una manifestación antitaurina que discurrió por las calles del centro de Barcelona hasta el Gobierno Civil, donde hicieron entrega de un comunicado para solicitar la abolición de las corridas de toros. Edición del lunes, 19 julio 1909, página 1 Hemeroteca Lavanguardia.es

1911: Despiadada y mordaz crítica a la vida muelle de los toreros y de sus acompañantes y de como trata la prensa edulcorada sus bodas y bautizos, en comparación con el trato que reciben los ciudadanos cultos, cívicos y trabajadores. Edición del domingo, 06 agosto 1911, página 6 - Hemeroteca Lavanguardia.es

1912: "La comisión abolicionista de las corridas de toros convoca á los que simpaticen con dicha abolición á la junta que tendrá efecto en el Ateneo Barcelonés, mañana, á las seis de la tarde. La reunión será presidida por don Tiberio Avila". Edición del martes, 19 marzo 1912, página 4 - Hemeroteca - Lavanguardia.es

1912: Con el levantamiento de la prohibición de celebrar corridas de toros los domingos se vive un "renacimiento" de la tortura nasioná. España se ha metido en una desastrosa guerra en Marruecos que desangra, aparte de vidas, la economía nacional y se le ha de dar un entretenimiento acorde con la situación a las masas embrutecidas. El articulista se queja de este hecho en un escrito titulado "La fiebre nacional". "El recrudecimiento de la afición á los toros que estamos presenciando indica cuan flaco 
servicio prestaron á la cultura nacional los que á última hora frustraron la iniciativa del señor La Cierva extendiendo la ley de descanso dominical á esta fiesta que no con orgullo, sino con bochorno ó disgusto oímos Ilamar nacional. En la temporada que no se celebraron en domingo, las corridas de toros iban de capa caída. Los convencidos de la popularidad de esta fiesta, los que pensaban que suprimirla era afrontar una revolución ó poco menos, se hacen cruces observando cómo un mero accidente cual el cambio del día, había hecho decaer la afición." Edición del sábado, 22 junio 1912, página 6 - Hemeroteca - Lavanguardia.es

1920: El articulista se mofa de manera descarada de una convocatoria taurina de aspirantes a torero y les tílda muy sutilmente de haraganes. "Sesenta y ocho aspirantes para una plaza de torero, es decir, para ponerse en condiciones de trepar a matador de cartel, Y no son muchos, si se tiene en cuenta que los españoles de diez y seis a cuarenta y cinco años sumamos varios millones. Para mí que muchos no han olido la breva, porque si se llega en el arte taurino al pináculo codiciado, eso de trabajar pasa a la categoría de lo ridículo".. Edición del viernes, 18 junio 1920, página $\begin{array}{lllll}8 & - & \text { Hemeroteca } & \text { L }\end{array}$

1926: Reunión de la Sociedad Protectora de Animales y Plantas de Cataluña en 1926. Entre otras medidas de protección a la fauna y la flora se encuentra esta: "Tercera.Que se llegue a la abolición de las corridas de toros, dictándose medidas cada día más restrictivas de un espectáculo tan inhumano y corruptor de las costumbres públicas". Edición del domingo, 14 marzo 1926, página 15 - Hemeroteca Lavanguardia.es

\section{RESUMIENDO:}

La identidad catalana rechaza las corridas de toros, pero no por oposición al resto de la Península, sino por su larga tradición como defensora de los derechos de los animales, que le ha llevado en el momento actuál a ser uno de los pocos países en Europa y única autonomía en el estado español en tener una legislación con "sacrificio cero" en la perreras, al desarrollo de una Ley de protección Animal, así como a prohibir la exposición de animales en escaparates con vistas a su venta, llegando a replantearse Barcelona tradiciones como la de los puestos de venta en las Ramblas, y habiendo sido la primera que prohibió la venta de pájaros ciegos.

De los 32 municipios que se han declarado Libres de circos con animales en España, 24 son catalanes (el último, el día 1 de marzo del presente año, Lloret de Mar), y son varios los que se han proclamado antitaurinos. 
Solo cuatro países (Alemania, Suiza, Austria y Cataluña) tienen un código civil que considera a los animales seres diferentes a las cosas, otorgándoles una naturaleza mixta y reconociéndoles una capacidad de sufrimiento tanto física como psíquicamente, lo que supone una responsabilidad moral muy importante para Cataluña.

Votar a favor de la ILP para la supresión de las corridas de toros en Cataluña no tiene nada que ver con ir contra la identidad española, sino que es un paso más en la lógica línea evolutiva del pueblo catalán. Pretender cortar esta línea, es un claro intento de "damnatio memoriae", con todo lo que comporta de pisotear su identidad moral, que se basa en valores éticos y no en una estética siempre subjetiva.

Cuando la ILP se apruebe, Cataluña será un poco más justa 